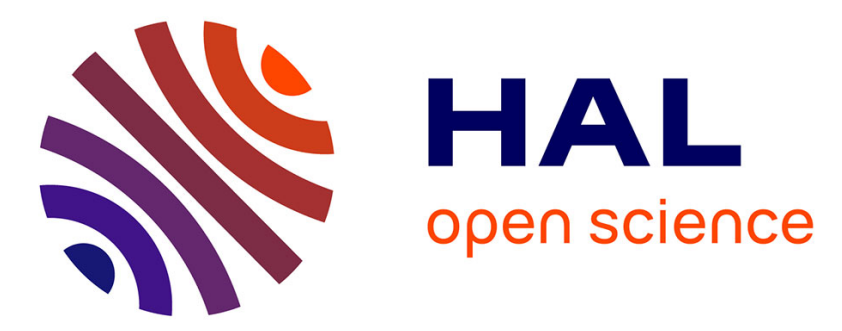

\title{
Change in porosity is the major determinant of the variation of cortical bone elasticity at the millimeter scale in aged women
}

Mathilde Granke, Quentin Grimal, Amena Saïed, Pierre Nauleau, Françoise Peyrin, Pascal Laugier

\section{To cite this version:}

Mathilde Granke, Quentin Grimal, Amena Saïed, Pierre Nauleau, Françoise Peyrin, et al.. Change in porosity is the major determinant of the variation of cortical bone elasticity at the millimeter scale in aged women. BONE, 2011, 49 (5), pp.1020-1026. 10.1016/j.bone.2011.08.002 . hal-01301976

\section{HAL Id: hal-01301976 https: / hal.sorbonne-universite.fr/hal-01301976}

Submitted on 13 Apr 2016

HAL is a multi-disciplinary open access archive for the deposit and dissemination of scientific research documents, whether they are published or not. The documents may come from teaching and research institutions in France or abroad, or from public or private research centers.
L'archive ouverte pluridisciplinaire HAL, est destinée au dépôt et à la diffusion de documents scientifiques de niveau recherche, publiés ou non, émanant des établissements d'enseignement et de recherche français ou étrangers, des laboratoires publics ou privés. 


\title{
Change in porosity is the major determinant of the variation of cortical bone elasticity at the millimeter scale in aged women
}

\author{
Authors: \\ Mathilde Granke a,b (mathilde.granke@gmail.com) \\ Quentin Grimal a,b (quentin.grimal@upmc.fr) \\ Amena Saïed ${ }^{\mathrm{a}, \mathrm{b}}$ (amena.saied@upmc.fr) \\ Pierre Nauleau ${ }^{\mathrm{a}, \mathrm{b}}$ (pierre.nauleau@upmc.fr) \\ Françoise Peyrin ${ }^{\mathrm{c}, \mathrm{d}}$ (peyrin@esrf.fr) \\ Pascal Laugier ${ }^{\mathrm{a}, \mathrm{b}}$ (pascal.laugier@upmc.fr)
}

a UPMC Univ Paris 06, UMR 7623, Laboratoire d'Imagerie Paramétrique, 75005 Paris, France

${ }^{\mathrm{b}}$ CNRS, UMR 7623, Laboratoire d'Imagerie Paramétrique, 75005 Paris, France

c CREATIS INSERM U1044; CNRS 5220; INSA Lyon; Université de Lyon, 69621

Villeurbanne Cedex, France

${ }^{\mathrm{d}}$ ESRF, 38043 Grenoble, France

\section{Corresponding author:}

Mathilde Granke

Laboratoire d'Imagerie Paramétrique, 15 rue de l'Ecole de Médecine, 75006 Paris, France tel: (+33) 1444149 74; fax: (+33) 14633 56 73; email: mathilde.granke@gmail.com 


\title{
1 Change in porosity is the major determinant of the variation of
} cortical bone elasticity at the millimeter scale in aged women

\begin{abstract}
At the mesoscale (i.e. over a few millimeters), cortical bone can be described as two-phase composite material consisting of pores and a dense mineralized matrix. The cortical porosity is known to influence the mesoscopic elasticity. Our objective was to determine whether the variations of porosity are sufficient to predict the variations of bone mesoscopic anisotropic elasticity or if change in bone matrix elasticity is an important factor to consider. We measured 21 cortical bone specimens prepared from the middiaphysis of 10 women donors (aged from 66 to 98 years). A 50-MHz scanning acoustic microscope (SAM) was used to evaluate the bone matrix elasticity (reflected in impedance values) and porosity. Porosity evaluation with SAM was validated against Synchrotron Radiation $\mu \mathrm{CT}$ measurements. A standard contact ultrasonic method was applied to determine the mesoscopic elastic coefficients. Only matrix impedance in the direction of the bone axis correlated to mesoscale elasticity (adjusted $\mathrm{R}^{2}=[0.16-0.25], \mathrm{p}<0.05$ ). The mesoscopic elasticity was found to be highly correlated to the cortical porosity $\left(\mathrm{adj}-\mathrm{R}^{2}=\right.$ [0.72 - 0.84], $\mathrm{p}<10^{-5}$ ). Multivariate analysis including both matrix impedance and porosity did not provide a better statistical model of mesoscopic elasticity variations. Our results indicate that, for the elderly population, the elastic properties of the mineralized matrix do not undergo large variations among different samples, as reflected in the low coefficients of variation of matrix impedance (less than 6\%). This work suggests that change in the intracortical porosity accounts for most of the variations of mesoscopic elasticity, at least when the analyzed porosity range is large (3-27\% in this study). The trend in the variation of mesoscale elasticity with porosity is consistent with the predictions of a micromechanical model consisting of an anisotropic matrix pervaded by cylindrical pores.
\end{abstract}

\section{Keywords:}

- $\quad$ anisotropic elasticity

- cortical porosity

- mechanical model

- scanning acoustic microscopy

- ultrasound 


\section{$1 \quad$ Introduction}

2 Bones of different individuals not only have different sizes and shapes, but also different

3 material properties. These characteristics entirely determine the elastic response of a bone

4 to a given mechanical loading. The elastic properties of cortical bone tissue, which has a

5 hierarchical organization, must be described in a multiscale framework: the structure and

6 mechanical properties at one hierarchical level determine the properties of the subsequent

7 one. The mesoscale designates the intermediate scale between the microscale (lamellar

8 structures) and the macroscale (organ level). More precisely, the characteristic size of a

9 mesoscopic volume will be larger than $1.5 \mathrm{~mm}$ [1] and smaller than the thickness of the

10 cortical shell. The mesoscale elastic properties are of first interest because they depend on

11 tissue properties at all small-scale hierarchical levels and they have a direct influence on the

12 macroscopic mechanical response of bones. The observed intra-individual [2] and inter-

13 individual $[3,4]$ variations of mesoscale elasticity are footprints of the remodeling process

14 and the structure-function adaptation mechanisms of bone. This calls for a clear

15 understanding of the variables that govern bone mesoscopic elasticity variations.

16 At the mesoscale, bone can be described as a two-phase composite material: a dense

17 mineralized matrix and a soft phase, hereinafter referred to as vascular porosity [5], which

18 consists of Haversian canals and resorption cavities containing fluids and soft tissues. The

19 porosity has been established to be an important determinant of the bone mesoscopic elastic

20 properties $[6,7,8]$. On the other hand, one would expect that variations of the mineralized

21 matrix properties strongly affect the mesoscopic elasticity because the matrix occupies

22 about $85 \%$ of the cortical bone volume. However, the actual influence of matrix properties

23 variations on mesoscale elasticity is still a matter of debate in the literature. Changes in 
1 matrix mineralization have been shown to be correlated with the mesoscopic mechanical

2 properties variations when the data were combined from eighteen species [9], but not when

3 only human data were considered [10]. Rho et al. [7] found that the matrix elasticity

4 (probed with nanoindentation) was significantly correlated to the mesoscopic axial Young's

5 modulus. Since both vascular porosity and matrix properties determine mesoscale elasticity,

6 it is not possible to draw general conclusions unless both porosity and matrix properties are

7 measured on the same samples. To our knowledge, only Rho et al. [7] investigated to what

8 extent the changes in porosity and matrix elasticity contribute to the variations of the

9 mesoscopic elasticity. They found a significant correlation of both variables with the

10 mesoscopic elasticity variations. Unfortunately, the elastic properties and the porosity were

11 assessed on different specimens and along the bone axis direction only. Human cortical

12 bone possesses anisotropic elastic properties which are often approximated by transversely

13 isotropic or orthotropic properties both at the microscale [11] and mesoscale [3,12]. The

14 preferential orientation of the pores and the mineralized fibrils are such that the

15 relationships between matrix properties, porosity and mesoscale elasticity may be

16 significantly different in the axial, radial and tangential directions of bone.

17 The objective of this work was to assess the relative contributions of vascular porosity and

18 mineralized matrix elasticity to the mesoscopic elasticity variations in mature human

19 cortical bone. To this purpose, experiments were designed following two requirements,

20 which constitute the originality of the work. First, the bone matrix elasticity (reflected in

21 acoustical impedance values) and porosity, as well as the mesoscopic elasticity, were

22 measured on the same samples. Second, elasticity measurements at both the micro and the

23 mesoscale were performed in three orthogonal directions. Finally, the experimental results 
1 were compared with the predictions of a micromechanical model to question the

2 assumption that cortical bone can be modeled as a homogeneous transversally isotropic

3 matrix pervaded by cylindrical pores.

4

$5 \quad$ Material and methods

$6 \quad$ Bone sample preparation

7 Fresh bone specimens were prepared from a collection of ten left femurs of female cadavers

8 (mean donor age 81 years, range 66-98 years). Femurs were removed during multi-organ

9 collection and stored at $-20^{\circ} \mathrm{C}$. Ethical approval for the collection of samples was granted

10 by the Human Ethics Committee of the Centre du don des Corps at the University Paris

11 Descartes (Paris, France). The tissue donors or their legal guardians provided informed

12 written consent to give their tissue for investigation, in accord with legal clauses stated in

13 the French Code of Public Health. A cross-section of thickness approximately $7 \mathrm{~mm}$ was

14 cut in the mid-diaphysis of each femur. In order to maximize the variability of bone

15 properties, parallelepiped-shaped samples were harvested from different anatomical

16 quadrants (lateral, medial, posterior) of each cross-section. No sample was extracted in

17 areas where the cortical thickness was less than $4 \mathrm{~mm}$. This led to a set of twenty-one

18 samples (nominally $5 \times 5 \times 7 \mathrm{~mm}^{3}$ ): three samples from two of the femurs, two samples

19 from seven other femurs and one sample from the remaining femur. The samples faces

20 were oriented according to the radial (axis 1), circumferential (axis 2), and axial (axis 3)

21 directions defined by the anatomic shape of the femoral diaphysis [2]. The samples were

22 defatted for 12 hours in a chemical bath of diethylether and methanol (1:1). The parallelism

23 of the opposite faces was controlled with a $50 \mu \mathrm{m}$ admitted error. The six faces of each 
1 sample were polished with a hard synthetic cloth using $3 \mu \mathrm{m}$ polycrystalline diamond

2 abrasive particles followed by a $0.05 \mu \mathrm{m}$ aluminum oxide suspension (Metadi Supreme and

3 Masterprep, Buehler ${ }^{\circledR} \mathrm{GmbH}$, Düsseldorf, Germany). After preparation, the samples were

4 stored in gauze soaked in saline solution at $4^{\circ} \mathrm{C}$ for no more than 48 hours prior to 5 measurements.

7 Assessment of mesoscale elasticity

8 Mesoscale elasticity was determined using a well-established method based on the 9 measurements of ultrasonic bulk wave velocities and sample apparent mass density. The 10 method, which has been extensively described elsewhere [2,12], is the only existing method 11 which provides measurements of the shear and longitudinal elastic properties in the 12 different directions of a same bone material volume. In contrast, mechanical methods 13 (traction, torsion, three-point bending, etc.) usually require to prepare one sample for the 14 measurement of each property. Given the ultrasonic bulk wave velocities $v$ and apparent 15 density $\rho$, the diagonal terms $\mathrm{C}_{\mathrm{ii}}$ of the mesoscopic elastic tensor are calculated from:

$16 \quad \begin{aligned} & C_{i i}=\rho \cdot v_{i i}^{2} \quad(i=1,2,3) \\ & C_{44}=\rho \cdot v_{23}^{2}=\rho \cdot v_{32}^{2} \\ & C_{55}=\rho \cdot v_{13}^{2}=\rho \cdot v_{31}^{2} \\ & C_{66}=\rho \cdot v_{12}^{2}=\rho \cdot v_{21}^{2}\end{aligned}$

17 where $\mathrm{C}_{11}, \mathrm{C}_{22}$, and $\mathrm{C}_{33}$ are the so called longitudinal elastic coefficients which represent 18 the stiffness in a traction-compression mode, and $\mathrm{C}_{44}, \mathrm{C}_{55}, \mathrm{C}_{66}$ are the shear coefficients. 19 Velocity $v_{j i}$ denotes the velocity of a bulk wave propagating in direction $i$ with particles 20 motion in the $j$-direction. For longitudinal waves, $i=j$, and for shear waves, $i \neq j$. Samples 
1 were measured undrained in ambient conditions. The apparent mass density of each sample

2 was assessed by dividing its mass by its volume; geometrical dimensions were measured

3 with a digital caliper (accuracy: $\pm 0.02 \mathrm{~mm}$ ) and mass with a laboratory scale (accuracy: \pm

$4 \quad 0.1 \mathrm{mg}$ ). The ultrasonic (US) wave velocities were evaluated using a pulse transmission

5 method with a pair of frequency matched transducers in contact with the sample surface.

6 Longitudinal waves and shear waves were measured using $2.25 \mathrm{MHz}$ and $1 \mathrm{MHz}$

7 transducers (respectively, V105RM and V152RM, Panametrics, Inc., Waltham, MA). Since

8 the longitudinal and shear wave velocities in bone are significantly different $(\sim 3700 \mathrm{~m} / \mathrm{s}$

9 and $1700 \mathrm{~m} / \mathrm{s}$, respectively), the use of different frequencies for these two propagation

10 modes allowed obtaining a similar wavelength, of the order of $1.7 \mathrm{~mm}$. Hence, the resulting

11 wavelength, which defines the probing scale, guaranteed to retrieve the bone mesoscopic

12 elasticity (i.e. at a scale much larger than the vascular pores). The received signal was

13 acquired using an oscilloscope (TDS 2012, Tektronix Inc., Beaverton, OR) and post-

14 processed with a custom MatLab program (The Mathworks Inc., Natick, MA). The time

15 delay, $\Delta \mathrm{t}$, for wave transmission through the specimen was obtained as the difference

16 between the arrival time of the US pulse with the sample inserted and the arrival time of a

17 reference signal (transducers in contact for the longitudinal waves, Plexiglas plate inserted

18 between the transducers for the shear waves). Each longitudinal coefficient was calculated

19 after averaging the velocities measured in ten successive acquisitions with intermediate

20 repositioning; each shear coefficient was obtained after averaging the two shear wave

21 velocities from which it could be calculated (equation (1)).

22 The accuracy of the elastic coefficients evaluation was determined from measurements on a

23 homogeneous calibrated pure polycrystalline (99.95\%) copper plate (Goodfellow SARL, 
1 Lille, France) and was found to be $2.1 \%$ and $0.9 \%$ for the longitudinal and shear elastic

2 coefficients, respectively. Measurement errors were assessed by repeating longitudinal and

3 shear waves velocity measurements on two human bone specimens for five consecutive

4 days with intermediate repositioning. The reproducibility was $3.2 \%$ and $4.7 \%$ for the

5 mesoscopic longitudinal and shear elastic coefficients, respectively. Finally, our

6 measurements were verified to be bulk wave velocities and not bar wave velocities [3]. For

7 this, longitudinal wave velocities were measured in eight artificial composite bone samples

8 (Sawbones, Pacific Research Laboratory Inc, Vashon WA) of dimensions $10 \times 20 \times d \mathrm{~mm}^{3}$

9 (thickness $\mathrm{x}$ cross-sectional dimension), the lateral dimension $d$ varying from 2 to $10 \mathrm{~mm}$.

10 The same velocity was measured for all the Sawbone samples $(2907 \pm 11 \mathrm{~m} / \mathrm{s})$. The value

11 corresponds to the tabulated bulk velocity for this material $(2890 \mathrm{~m} / \mathrm{s})$. Thus, the velocities

12 measured in this study, even for the smallest samples, were proved to be bulk wave

13 velocities and equation (1) can be applied to derive the elastic coefficients.

$15 \quad 50-\mathrm{MHz}$ Scanning Acoustic Microscopy

16 A custom scanning acoustic microscope (SAM), operating with a spherically focused 50-

$17 \mathrm{MHz}$ transducer (V605, Valpey Fisher, Hopkinton, USA), was used to probe the acoustic

18 impedance normal to the samples surfaces according to the measurement procedure

19 extensively detailed in previous studies $[13,14]$. The acoustic impedance $(Z)$, which is

20 modeled as the square root of the product of the local mass density and elastic coefficient in

21 the beam direction, has been shown to be a surrogate measurement of the bone matrix

22 elasticity at the microscale [15]. This is also reflected by the good agreement between the

23 impedance and the Young's modulus of bone matrix as obtained from site-matched SAM 
1 and nanoindentation measurements in bone [16,17] (although some discrepancies appear

2 presumably due to the assumptions made on the Poisson ratio). Calibrated impedance maps

3 were obtained with a lateral resolution of $30 \mu \mathrm{m}$ for all six faces of each sample. The $Z$ -

4 maps were segmented allowing the separation of vascular porosity and bone matrix as

5 previously reported [18].

6 The acoustic impedance of the matrix was determined from the segmented maps for each

7 face of the twenty-one samples. Note that the small pores (Volkmann's canal, osteocyte

8 lacunae) could not be resolved so that they contributed to the probed bulk matrix properties.

9 Matrix impedance in the probing direction, denoted $\hat{Z}_{i}(\mathrm{i}=1,2,3)$, was defined as the average

10 of the impedance values of the matrix pixels in two opposite faces of normal $n_{i}(i=1,2,3)$.

11 The reproducibility of the assessment of $\hat{Z}$, obtained after imaging the face of the same

12 bone four times on different days, was found to be $1.4 \%$.

13 The 2D cross-sectional porosity was calculated from the segmented Z-maps in the 1-2

14 plane, i.e. perpendicular to the bone axis (Fig. 1), as the ratio of the pores area to the total

15 bone surface. Porosity is usually assumed to vary only slightly across sample thickness.

16 This assumption is reasonably met with the typical sample thickness of $7 \mathrm{~mm}$, given that

17 (1) the Haversian canals are roughly aligned with the bone axis and (2) the osteon length is

$184 \mathrm{~mm}$ on average in human femoral mid-diaphysis [19]. However in our experience, large

19 resorption cavities visible on a cross-sectional surface can introduce a significant bias in the

20 estimation of volumetric porosity from surface porosity. To overcome this limitation, we

21 estimated the volumetric porosity of each sample (denoted Por) as the average value of the

22 cross-sectional porosities assessed on the two opposite faces in the 1-2 planes. 
2 Synchrotron Radiation Microtomography $(S R-\mu C T)$

3 To comfort our assumption that Por is a good surrogate for the volumetric porosity, a

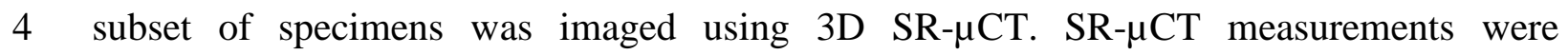

5 performed on the imaging beamline ID19 at the ESRF (European Synchrotron Radiation

6 Facility, Grenoble, France). The beam energy was tuned to $27 \mathrm{keV}$ by using a (Si111)

7 double crystal monochromator. A full set of 2D radiographic images was recorded using a

8 CDD detector (FReLoN camera; ESRF Detector group) by rotating the sample in 1999

9 steps within a $360^{\circ}$ range of rotation in about 35 minutes. We selected a pixel size of $5.4 \mu \mathrm{m}$

10 on the detector providing a 3D reconstructed image volume with a measured spatial

11 resolution of about $10 \mu \mathrm{m}$. Due to time limitations at the ESRF facilities, only ten of the

12 twenty-one samples were imaged. After the 3D tomographic reconstruction and the

13 conversion of the linear attenuation coefficients to degree of mineralization values

14 expressed in $\mathrm{g} / \mathrm{cm}^{3}$ of hydroxyapatite (HA) crystals [20], the 3D-porosity was derived from

15 the segmented $\mathrm{SR} \mu \mathrm{CT}$ images, following a fixed threshold set to $0.7 \mathrm{~g} \mathrm{HA} / \mathrm{cm}^{3}$.

16

17 Micromechanical model

18 Micromechanical models are useful as a means of testing how changes of the bone

19 microscale properties affect its mesoscopic behavior. The modeled behavior depends in

20 particular on hypothesized organizational patterns and elastic symmetry of the model

21 material phases. In this work, a model of cortical bone mesoscopic elasticity based on

22 asymptotic homogenization (AH) was used (source code available online [21]). This

23 micromechanical method was chosen for its stability, even at high porosities. The theory 
1 was described in details in the case of matrix isotropy in Parnell and Grimal [22]. The

2 model hypothesizes that cortical bone can be regarded as a homogeneous transversely

3 isotropic (TI) matrix pervaded by cylindrical pores, which are periodically distributed

4 within the matrix material, specifically on a hexagonal lattice (Fig. 1). Here, the plane

5 normal to the pores (1-2 plane) is the plane of isotropy for the matrix. The representation

6 leads to transversely isotropic elasticity at the mesoscale (isotropy in the 1-2 plane), which

7 is a reasonable approximation in human femoral mid-diaphysis [2,12]. Given an elastic

8 tensor $c^{m}$ describing the matrix elasticity, an elastic tensor $c^{p}$ describing the elasticity of

9 the material within the pores, and the volume fraction of pores, a homogenized elastic

10 tensor $\mathrm{C}^{*}$ at the mesoscale is calculated. The elastic tensor of the bone matrix was identical

11 for all samples. Its coefficients were determined by minimizing the L2-norm of the relative

12 error between the experimental $(\mathrm{C})$ and homogenized $\left(\mathrm{C}^{*}\right)$ mesoscopic elasticity values

13 over the twenty-one samples. Hence $c^{m}$ is the tensor which minimizes the objective

14 function defined as:

$15 \quad H_{0}\left(c^{m}\right)=\sqrt{\sum_{k=1}^{21} \sum_{i=1}^{6}\left(\frac{C_{i i ; k}-C_{i i ; k}^{*}\left(c^{m}, c^{p}, \text { Por }_{k}\right)}{C_{i i ; k}}\right)^{2}}$

16 where Pork $_{k}$ refers to the estimate of porosity of sample $k$ assessed from impedance maps,

17 and $C_{i i: k}$ and $C_{i i ; k}^{*}$ to its experimental and homogenized elastic coefficients. Since the

18 samples were kept moist during the measurements, the material in pores (undrained) was

19 assumed to behave like bulk water, that is, bulk modulus and Poisson ratio were set to 2.3

$20 \mathrm{GPa}$ [23] and 0.4999 (quasi-incompressible), respectively, from which the terms of $c^{p}$ can

21 be calculated. 
2 Statistics

3 The distribution normality and variance equality were confirmed using Shapiro-Wilk and

4 Bartlett's tests respectively. One-way analysis of variance (ANOVA) followed by post-hoc

5 comparisons using Tukey's HSD test were performed to evaluate the differences in the

6 different directions for the longitudinal and shear elastic coefficients and for the mean

7 acoustic impedance. Note that the influence of the anatomical quadrant on the elasticity was

8 not investigated due to the small number of samples (posterior $(n=2)$, lateral $(n=9)$, and

9 medial $(n=10))$. Adjusted $\mathrm{R}^{2}\left(\operatorname{adj}-\mathrm{R}^{2}\right)$ from single linear and stepwise multiple regression

10 analyses were used to characterize the relative contributions of the vascular porosity (Por)

11 and bone matrix mean impedance in the different directions $\left(\hat{Z}_{i}\right)$ to the mesoscopic elastic

12 coefficients $\left(\mathrm{C}_{\mathrm{ii}}\right)$. After the determination of the optimal matrix properties $c^{m}$ in the $\mathrm{AH}$

13 model (equation 2), the agreement between the experimental and homogenized elastic

14 coefficients as obtained from the $\mathrm{AH}$ model was deduced from the linear regression

15 parameters (adj- $\mathrm{R}^{2}$ and root mean square error (RMSE)). All statistical results were

16 considered significant for $\mathrm{p}$-values less than 0.05. Statistics were made using the MatLaB

17 Statistics Toolbox (The Mathworks Inc., Natick, MA, USA) and JMP (SAS Institute Inc., 18 Cary, NC).

\section{Results}

21 We evaluated the anisotropic elastic properties of the samples at two scales. At the 22 mesoscale, ANOVA showed that the samples exhibited a strong elastic anisotropy which 
1 was reflected in the longitudinal elastic coefficients $\left(F=98, p<10^{-5}\right)$ as well as in the shear

2 elastic coefficients $\left(F=26, p<10^{-5}\right)$. Precisely, we observed (Tukey HSD) $\mathrm{C}_{33}>\mathrm{C}_{11}$ (not

3 different from $\mathrm{C}_{22}$ ) and $\mathrm{C}_{66}<\mathrm{C}_{44}$ (not different from $\mathrm{C}_{55}$ ). At the microscale, the bone

4 matrix also exhibited anisotropy $\left(\mathrm{F}=96, \mathrm{p}<10^{-5}\right)$, which was reflected in a significant

5 higher impedance value along the bone axis compared to the two transverse directions

$6 \hat{Z}_{1}$ and $\hat{Z}_{2}$, which did not significantly differ. The average values of the mesoscopic elastic

7 coefficients and the bone matrix mean impedance are summarized in Table 1 . The p-values

8 of the Tukey tests are given in Figure 2.

9 The comparison, for a subset of ten samples, of the 3D-porosity obtained from the SR- $\mu \mathrm{CT}$

10 to the estimated porosity value (Por) allowed to validate the assessment of volumetric

11 porosity from the segmented impedance maps. Precisely, Por and the 3D-porosity were not

12 significantly different (paired t-test, $\mathrm{p}=0.48$ ) and were highly correlated as shown by the

13 linear regression results $\left(\operatorname{adj} \mathrm{R}^{2}=0.98, \mathrm{RMSE}=0.94 \%\right.$, slope not significantly different

14 from 1) (Fig. 3). Por was found to be (mean \pm sd) $13.5 \pm 6.8 \%$, covering a wide range of

15 values [3-27\%].

16 A weak but significant correlation was found between all $\mathrm{C}_{\mathrm{ii}}$, except $\mathrm{C}_{22}$, and $\hat{Z}_{3}$ (bone axis

17 direction) (adj- $\mathrm{R}^{2}<0.25, \mathrm{p}=[0.01-0.04]$ ) (Table 2). No significant correlation was found

18 between the $\mathrm{C}_{\mathrm{ii}}$ and the matrix impedance in the radial and circumferential directions

$19\left(\hat{Z}_{1}\right.$ and $\left.\hat{Z}_{2}\right)$. The mesoscopic elastic coefficients were well correlated to the porosity (adj-

$\left.20 \mathrm{R}^{2}=[0.72-0.84], \mathrm{p}<10^{-5}\right)$. The use of a stepwise regression analysis showed no

21 improvement of the correlation when adding the bone matrix impedance $\left(\hat{Z}_{i}\right)$ to the

22 porosity to explain the mesoscopic elasticity variations between samples. 
1 The transversely isotropic elastic tensor of the matrix $\left(c^{m}\right)$ which allowed the best

2 agreement (in the sense of equation 2) between measured and modeled mesoscopic elastic

3 properties was found to be $c_{11}^{m}=c_{22}^{m}=26.8 \mathrm{GPa}, c_{33}^{m}=35.1 \mathrm{GPa}, c_{44}^{m}=c_{55}^{m}=7.3 \mathrm{GPa}$,

$4 \quad c_{66}^{m}=5.8 \mathrm{GPa}, c_{13}^{m}=c_{23}^{m}=15.3 \mathrm{GPa}$, and thus $c_{12}^{m}=c_{11}^{m}-2 c_{66}^{m}=15.2 \mathrm{GPa}$.

5 The experimental mesoscopic elastic coefficients correlated well with the effective elastic

6 coefficients as computed from the AH model (adj- $\left.\mathrm{R}^{2}=[0.78-0.82], \mathrm{p}<10^{-5}\right)$ (Fig. 4). The

7 precision of the model prediction was evaluated by means of the RMSE absolute and

8 relative values: $\mathrm{C}_{11}=1.0 \mathrm{GPa}(5.2 \%), \mathrm{C}_{22}=1.2 \mathrm{GPa}(6 \%), \mathrm{C}_{33}=1.7 \mathrm{GPa}(5.6 \%), \mathrm{C}_{44}=0.3$

$9 \mathrm{GPa}(5.5 \%), \mathrm{C}_{55}=0.4 \mathrm{GPa}(8.5 \%), \mathrm{C}_{66}=0.3 \mathrm{GPa}(7.6 \%)$.

\section{Discussion}

12 To our knowledge, the current work is the first to provide, for the same set of samples,

13 measurements of the anisotropic elastic properties at two scales together with an evaluation

14 of the cortical porosity. A set of human femoral cortical bone data, obtained on twenty-one

15 samples from ten donors, was used to investigate the relative contributions of both the

16 matrix elasticity and the porosity to the bone mesoscopic elasticity.

17 The experimental data corroborated well with previous studies, be it in respect of the 18 mesoscopic elastic coefficients [2,3,12], the mean acoustic impedance of the bone matrix $19[14,17]$, or the range of the intracortical porosity $[24,25,26]$.

20 Impedance measurements suggested that the average elastic properties of the mineralized

21 matrix did not undergo large variations in the different samples (with coefficients of

22 variation of the $\hat{Z}_{i}$ all inferior to $6 \%$ ). The limited variations of bone matrix elasticity 
1 reflected in $Z$ might explain the lack of correlation between the mean acoustic impedance of

2 the matrix and the mesoscopic elastic coefficients. A literature review reveals that such

3 modest variations of the bone matrix properties have been observed in a number of studies.

4 Cross-sectional reports have shown that the mean degree of mineralization of bone does not

5 exhibit large variations between individuals, independently of age $[10,27,28]$ and gender

6 [27]. A few studies have measured the matrix elasticity on several individuals at the same

7 cortical bone site (femoral diaphysis and neck [29], femoral diaphysis [7], radius [14]).

8 Similarly, they all reported small changes in the mean value of the matrix elasticity

9 (average of several measurements points on a surface of at least $1 \mathrm{~mm}$ ) with coefficients of

10 variation ranging between 3 and $10 \%$. Hence, although the bone matrix elasticity is known

11 to display strong local heterogeneities (in particular between the osteonal and interstitial

12 tissues), its mean value over a few millimeters remains relatively constant in healthy

13 individuals. However, a selection of bone specimens in a population with known bone

14 pathologies could result in a wider variation of matrix material properties and lead to

15 different conclusions.

16 Our results demonstrate that, for an elderly population, the change in porosity is the major

17 determinant of the variations of the anisotropic elastic coefficients at the mesoscale, at least

18 in the femoral mid-diaphysis. To our knowledge, only one study has experimentally

19 examined the impact of porosity variations on the elasticity of human femoral cortical bone

20 in several directions [8]. While they also found a strong dependence of the Young's moduli

21 and shear moduli on porosity $\left(\mathrm{R}^{2}=[0.66-0.72]\right)$, they observed no significant correlation

22 between the elastic properties in the transverse direction and the porosity, in contrast to our

23 findings. 
1 The fact that all the mesoscopic elastic coefficients have a dependency on the porosity is

2 supported by the theoretical results obtained with several models using different

3 homogenization approaches [1,30,31,32,33,34]. We compare the outcome of a

4 homogenization model to experimental data for known values of porosities associated to a

5 number of bone material volumes. As far as we know, only two previous studies confronted

6 experimental results with the predictions of a micromechanical model. However, the elastic

7 constants were not assessed on the same specimens [31], or the shear constants were

8 lacking [35]. In our study, because six elastic coefficients have been measured for each

9 sample, a large data set is available for the comparison. We found that modeling cortical

10 bone as a two-phase composite with a transversely isotropic matrix pervaded by cylindrical

11 pores provided a good estimate of the elasticity variations at the mesoscale, as shown by the

12 strong correlations (relative RMSE $=[5.2-8.5 \%]$ ) between the experimental results and

13 the prediction of the micromechanical model. Note, however, that the homogenized

14 elasticity $\mathrm{C}^{*}$ is not strictly independent of the mesoscale experimental data $\mathrm{C}$ because the

15 matrix elasticity of the model $\left(c^{m}\right)$ was determined such that the agreement between $\mathrm{C}$ and

$16 \mathrm{C}^{*}$ is optimum (equation 2).

17 It is noteworthy that the model was particularly efficient considering its ability to fit all

18 experimental mesoscopic elastic coefficients with a relatively good accuracy using a unique

19 elastic tensor for the matrix and the pores and a sample-dependent porosity. This was

20 despite the many idealizations of the model, in particular the elastic properties of the matrix

21 and the modeling of the pores. Universal, homogeneous, elastic properties were assigned to

22 the bone matrix. The choice of a unique matrix was supported by the small change in the 
1 average elastic properties of the matrix, as testified by the matrix impedance data. We

2 verified that the optimized set of TI elastic properties assigned to the bone matrix $\left(c^{m}\right)$

3 were physically acceptable. In fact, once converted into engineering moduli $\left(\mathrm{E}_{\mathrm{T}}=16.5\right.$

$4 \mathrm{GPa}, \mathrm{E}_{\mathrm{L}}=24.0 \mathrm{GPa}, \mathrm{G}_{\mathrm{T}}=5.8 \mathrm{GPa}, \mathrm{G}_{\mathrm{L}}=7.3 \mathrm{GPa}$ ), the matrix elastic properties were found

5 consistent with the nanoindentation values in human femoral bone available in literature

$6 \quad[36,37,38]$. Moreover, the matrix elastic coefficients $\left(c^{m}\right)$ used in our model compared well

7 with those derived from the experimental acoustic impedance mean values using the

8 conversion relationship between $\mathrm{Z}$ and $c^{m}$ [15]. Precisely, the elastic coefficients of the

9 matrix as derived from the $\mathrm{Z}_{\mathrm{i}}(\mathrm{i}=1,2,3)\left(c_{11}^{m \exp }=28.7 \pm 3.1 \mathrm{GPa}, c_{22}^{m \exp }=28.5 \pm 2.3 \mathrm{GPa}\right.$ and

$\left.10 \quad c_{33}^{m \exp }=40.7 \pm 3.3 \mathrm{GPa}\right)$ were in agreement with the elastic coefficients assigned in the

11 model $\left(c_{11}^{m}=c_{22}^{m}=26.8 \mathrm{GPa}, c_{33}^{m}=35.1 \mathrm{GPa}\right)$. The vascular porosity was idealized as

12 infinite cylinders of circular cross-section aligned along the bone long axis. Hence, the

13 pores were modeled as continuous even though a discontinuous representation might seem

14 more realistic. However, we have found that, for aspect ratios (length of the pore / diameter

15 of the pore) larger than 5, modeling the pores as infinite cylinders yields a very good

16 approximation (less than $1 \%$ error) of discontinuous pores with typical aspect ratio of the

17 Haversian canal [39]. Although this representation has been commonly used for modeling

18 cortical bone [30,31,35], it does not take into account the variability of pores shapes, size,

19 and distribution. Considering the gradient of porosity from the endosteal to the periosteal

20 region $[14,24]$ or the change in the pores size [26,32] may improve the predictions of the

21 bone effective elastic properties. 
1 The remaining part of experimentally determined elasticity $\mathrm{C}$ which is not explained by the

2 model is due to experimental uncertainties and model assumptions. The latter comprise the

3 assumptions regarding the pores as mentioned above and the fact that some variability of

4 the matrix properties exists between different samples.

5 A first limitation of the study arises from the estimation of the sample porosity as the

6 average value of the cross-sectional porosities assessed on the two opposite transverse

7 faces. However, the validation of the porosity evaluation with 2D SAM on ten samples

8 against the vascular porosity as obtained from 3D SR $\mu$ CT data confirmed that Por is a good

9 proxy for the vascular porosity. A second limitation in the study is the fact that all donors

10 were elderly female donors (with a mean age superior to 80 years). Although the bone

11 matrix elasticity has been shown to be independent from age and gender [40], aging

12 strongly affects the range of porosity and could change the relative contributions of the

13 matrix elasticity and the porosity to the mesoscopic elasticity in younger individuals. Thus

14 the conclusions of this study hold true only for an aged population, which is most

15 commonly affected by osteoporosis and bone fragility. Finally, in spite of a limited sample

16 size ( $\mathrm{n}=21$ from 10 subjects), the range of values covered by the porosity (from 3 to $27 \%$ )

17 was wide enough to provide conclusive results.

18 In summary, the findings of this paper demonstrate that, in aged women, the changes in 19 porosity prevail over those of matrix elasticity to drive the variations of the bone 20 mesoscopic elasticity. The impact of the porosity on the elasticity is all the more important

21 considering the increased intracortical porosity as a consequence of aging $[10,26,41,42,43]$

22 and disease, e.g. hyperparathyroidism, osteoporosis [44]. In particular, Zebaze et al. [43]

23 showed that $84 \%$ of the bone loss occurs after the age of 65 of which $68 \%$ would be 
1 cortical bone manifested as an increase of cortical porosity. Moreover, the increase of

2 cortical porosity, pointed out as the dominant factor occurring in elderly individuals, is

3 known to reduce bone strength [45]. A simple mechanical model was proposed to interpret

4 the experimental data: the dependence on porosity of shear and longitudinal elastic

5 properties in the radial, circumferential, and axial directions of bone is correctly described

6 when idealizing bone as a two-phase material with a 'universal' (same for all bone samples)

7 transversely isotropic matrix pervaded by cylindrical pores.

10 Acknowledgments

11 This work has been conducted within the European Associated Laboratory "Ultrasound 12 Based Assessment of Bone" (ULAB) and was supported by the ESRF Long Term Proposal 13 MD431. 


\section{1}

11 elastic inhomogeneity and anisotropy of human femoral cortical bone tissue is consistent

12 across multiple donors. J Biomech 2011;doi:10.1016/j.jbiomech.2011.04.009.

13 [5] Cowin SC. Bone poroelasticity. J Biomech 1999;32:217-238.

\section{References}

[1] Grimal Q, Raum K, Gerisch A, Laugier P. A determination of the minimum sizes of representative volume elements for the prediction of cortical bone elastic properties. Biomech Model Mechanobiol 2011;doi:10.1007/s10237-010-0284-9.

[2] Espinoza Orias AA, Deuerling JM, Landrigan MD, Renaud JE, Roeder RK. Anatomic variation in the elastic anisotropy of cortical bone tissue in the human femur. J Mech Behav Biomed Mater 2009;2:255-263.

[3] Ashman RB, Cowin, SC, Van Buskirk WC, Rice JC. A continuous wave technique for the measurement of the elastic properties of cortical bone. J Biomech 1984;17:349-361. [4] Rudy DJ, Deuerling JM, Espinoza Orias AA, Roeder RK. Anatomic variation in the [6] Wachter NJ, Krischak GD, Mentzel M, Sarkar MR, Ebinger T, Kinzl L, Claes L, Augat P. Correlation of bone mineral density with strength and microstructural parameters of cortical bone in vitro. Bone 2002;31:90-95.

[7] Rho JY, Zioupos P, Currey JD, Pharr GM. Microstructural elasticity and regional heterogeneity in human femoral bone of various ages examined by nanoindentation. J Biomech 2002;35:189-198.

[8] Dong XN, Guo XE. The dependence of transversely isotropic elasticity of human femoral cortical bone on porosity. J Biomech 2004;37:1281-1287.

[9] Currey JD. The effect of porosity and mineral content on the Young's modulus of elasticity of compact bone. J Biomech 1988;21:131-139. 
1 [10] McCalden RW, McGeough JA, Barker MB, Court-Brown CM. Age related changes in

2 the tensile properties of cortical bone. J Bone Joint Surg Am 1993;75:1193-1205.

3 [11] Currey JD, Zioupos P. The effect of porous microstructure on the anisotropy of bone-

4 like tissue: a counterexample. J Biomech 2001;34:707-708.

5 [12] Yoon HS, Katz JL. Ultrasonic wave propagation in human cortical bone - II.

6 Measurements of elastic properties and microhardness. J Biomech 1976;9:459-464.

7 [13] Raum K, Leguerney I, Chandelier F, Bossy E, Talmant M, Saïed A, Peyrin F, Laugier

8 P. Bone microstructure and elastic tissue properties are reflected in QUS axial transmission

9 measurements. Ultrasound Med Biol 2005;31:1225-1235.

10 [14] Saïed A, Raum K, Leguerney I, Laugier P. Spatial distribution of anisotropic acoustic

11 impedance assessed by time-resolved 50-MHz scanning acoustic microscopy and its

12 relation to porosity in human cortical bone. Bone 2008;43:187-194.

13 [15] Preininger B, Checa S, Molnar FL, Fratzl P, Duda GN, Raum K. Spatial-temporal 14 mapping of bone structural and elastic properties in a sheep model following osteotomy.

15 Ultrasound Med Biol 2011;37:474-483.

16 [16] Hofmann T, Heyroth F, Meinhard H, Franzel W, Raum K. Assessment of composition 17 and anisotropic elastic properties of secondary osteon lamellae. J Biomech 2006;39:2282182294.

19 [17] Rupin F, Saïed A, Dalmas D, Peyrin F, Haupert S, Raum K, Barthel E, Boivin G, 20 Laugier P. Assessment of Microelastic Properties of Bone Using Scanning Acoustic 21 Microscopy: A Face-to-face Comparison with Nanoindentation. Jpn J Appl Phys $22 \quad 2009 ; 48: 07$ GK01. 
1 [18] Raum K, Leguerney I, Chandelier F, Talmant M, Saïed A, Peyrin F, Laugier P. Site-

2 matched assessment of structural and tissue properties of cortical bone using scanning

3 acoustic microscopy and synchrotron radiation $\mu$ CT. Phys Med Biol 2006;51:733-746.

4 [19] Cooper DML, Thomas CDL, Clement JG, Hallgrimsson B. Three-dimensional 5 microcomputed tomography imaging of basic multicellular unit-related resorption spaces in 6 human cortical bone. Anat Rec A 2006;228A:806-816.

7 [20] Nuzzo S, Peyrin F, Cloetens P, Baruchel J, Boivin G. Quantification of the degree of 8 mineralization of bone in three dimensions using synchrotron radiation microtomography.

9 Med Phys 2002;29:2672-2681.

10 [21] Grimal Q, Parnell WJ. Cortical bone homogenization. Retrieved January 15, 2011 11 from http://www.labos.upmc.fr/lip/spip.php?rubrique133.

12 [22] Parnell WJ, Grimal Q. The influence of mesoscale porosity on cortical bone 13 anisotropy. Investigations via asymptotic homogenization. J R Soc Interface 2009;6:9714109.

15 [23] Anderson CB. Mechanics of fluids. In: Baumeister T (Ed.). Mark's saturated handbook 16 for mechanical engineers. MacGraw-Hill, New York 1967;pp.3.48-3.76.

17 [24] Bousson V, Bergot C, Meunier A, Barbot F, Parlier-Cuau C, Laval-Lantet AM, Laredo 18 JD. CT of the middiaphyseal femur: cortical bone mineral density and relation to porosity. 19 Radiology 2000;217:179-187.

20 [25] Thomas CDL, Feik SA, Clement JG. Regional variation of intracortical porosity in the 21 midshaft of the human femur: age and sex differences. J Anat 2005;206:115-125. 
1 [26] Cooper DML, Thomas CDL, Clement JG, Turinsky AL, Sensen CW, Hallgrimson B.

2 Age-dependent change in the 3D structure of cortical porosity at the human femoral 3 midshaft. Bone 2007;40:957-965.

4 [27] Boivin G, Meunier PJ. The degree of mineralization of bone tissue measured by 5 computerized quantitative contact microradiography. Calcif Tissue Int 2002;70:503-511.

6 [28] Bergot C, Wu Y, Jolivet E, Zhou LQ, Laredo JD, Bousson V. The degree of 7 mineralization in the human femoral shaft change with age and sex in a microradiographic 8 study. Bone 2009;45:435-442.

9 [29] Hoffler CE, Moore KE, Kozloff K, Zysset PK, Brown MB, Goldstein SA. 10 Heterogeneity of bone lamellar-level elastic moduli. Bone 2000;26:603-609.

11 [30] Hellmich C, Ulm FJ, Dormieux L. Can the diverse elastic properties of trabecular and 12 cortical bone be attributed to only a few tissue-independent phase properties and their 13 interactions? Biomech Model Mechanobiol 2004;2:219-238.

14 [31] Dong XN, Guo XE. Prediction of cortical bone elastic constants by a two-level 15 micromechanical model using a generalized self-consistent method. J Biomed Eng $162006 ; 128: 309-316$.

17 [32] Baron C, Talmant M, Laugier P. Effect of porosity on effective diagonal stiffness 18 coefficients $\left(c_{i i}\right)$ and elastic anisotropy of cortical bone at $1 \mathrm{MHz}$ : a finite-difference time 19 domain study. J Acoust Soc Am 2007;122:1810-1817.

20 [33] Grimal Q, Raum K, Gerisch A, Laugier P. Derivation of the mesoscopic elasticity 21 tensor of cortical bone from quantitative impedance images at the micron scale. Comput 22 Meth Biomech Biomed Eng 2008;11:147-157. 
1 [34] Grimal Q, Rus G, Parnell WJ, Laugier P. A two-parameter model of the effective

2 elastic tensor for cortical bone. J Biomech 2011;44:1621-1625.

3 [35] Deuerling JM, Weimin Y, Espinoza Orias AA, Roeder RK. Specimen-specific multi-

4 scale model for the anisotropic elastic constants of human cortical bone. J Biomech $5 \quad$ 2009;42:2061-2067.

6 [36] Rho JY, Roy II ME, Tsui TY, Pharr GM. Elastic properties of microstructural 7 components of human bone tissue as measured by nanoindentation. J Biomed Mater Res A $8 \quad 1999 ; 45: 48-54$.

9 [37] Turner CH, Rho JY, Takano Y, Tsui TY, Pharr GM. The elastic properties of 10 trabecular and cortical bone tissues are similar: results from two microscopic measurements 11 techniques. J Biomech 1999;32:437-441.

12 [38] Franzoso G, Zysset PK. Elastic anisotropy of human cortical bone secondary osteons 13 measured by nanoindentation. J Biomech Eng 2009;131:021001-1.

14 [39] Granke M, Grimal Q, Parnell WJ, Saïed A, Peyrin F, Laugier P. Elasticity and porosity 15 in human cortical bone: models and experiments. In Congrès Français de Mécanique, 16 Besançon 2011.

17 [40] Hoffler CE, Moore KE, Kozloff K, Zysset PK, Goldstein SA. Age, gender, and bone 18 lamellae elastic moduli. J Orthop Res 2000;18:432-437.

19 [41] Bousson V, Meunier A, Bergot C, Vicaut E, Rocha MA, Morais MH, Laval-Jantet 20 AM, Laredo JD. Distribution of intracortical porosity in human midfemoral cortex by age 21 and gender. J Bone Miner Res 2001;16:1308-1317. 
1 [42] Burghardt AJ, Kazakia GJ, Ramachandran S, Link TM, Majumdar S. Age- and 2 gender-related differences in the geometric properties and biomechanical significance of 3 intracortical porosity in the distal radius and tibia. J Bone Miner Res 2010;25:983-993.

4 [43] Zebaze R, Ghasem-Zadeh A, Bohte A, Iuliano-Burns S, Mirams M, Ian Price R, 5 Mackie EJ, Seeman E. Intracortical remodeling and porosity in the distal radius and post6 mortem femurs of women: a cross-sectional study. The Lancet 2010;375:1729-1736.

7 [44] Chavassieux P, Seeman E, Delmas PD. Insights into material and structural basis of 8 bone fragility from diseases associated with fractures: how determinants of the 9 biomechanical properties of bone are compromised by disease. Endocr Rev 2007;28:15110164.

11 [45] Yeni YN, Brown CU, Wang Z, Norman TL. The influence of bone morphology on 12 fracture toughness of the human femur and tibia. Bone 1997;21:453-459. 


\section{$1 \quad$ Figures captions}

2 Figure 1 (a) 3D reconstruction of a cortical bone volume from SR- $\mu \mathrm{CT}$ data. The samples

3 faces are oriented according to the radial (1), circumferential (2), and axial (3) axes defined

4 by the anatomic shape of the femoral diaphysis. (b) Idealization of cortical bone as a 5 homogeneous anisotropic matrix pervaded by infinite cylindrical pores, which are

6 periodically distributed within the matrix material, specifically on a hexagonal lattice.

8 Figure 2 Experimental results: (a) mesoscopic elastic coefficients (b) mean acoustic 9 impedance of the bone matrix. On each box the central mark is the median, the edges are 10 the $25^{\text {th }}$ and $75^{\text {th }}$ percentiles, the whiskers extend indicate the extreme values. The $p$-values 11 from the post hoc multiple comparison Tukey's HSD tests are also given.

13 Figure 3 Validation of the assessment of volumetric porosity from the segmented 14 impedance maps on a subset of ten samples: the estimated value of the 'volumetric' 15 porosity (Por) is plotted against the 3D-porosity obtained from SR- $\mu \mathrm{CT}$.

16

17 Figure 4 (a) Longitudinal and (b) shear mesoscopic elastic coefficients versus porosity:

18 results from experiments $(\mathbf{\square}, \mathrm{o}, \boldsymbol{\Delta})$ and asymptotic homogenization model solid and dotted 19 lines). Note that all the homogenized elastic coefficients computed from the AH model are 20 obtained using a unique set of elastic constants for the bone matrix. 


\section{Tables captions}

2 Table 1 Experimental data (mean \pm std [range])

3

4 Table 2 Multivariate analysis regression (adjusted $\mathrm{R}^{2}$ and RMSE): relative contributions

5 of the vascular porosity (Por) and the matrix impedance $\left(\hat{Z}_{i}\right)$ to the mesoscopic elastic 6 coefficients $\left(\mathrm{C}_{\mathrm{ii}}\right)$. 


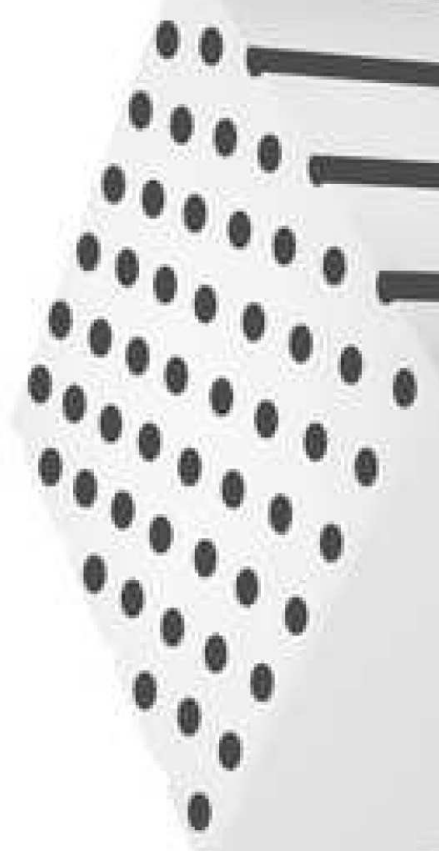

으

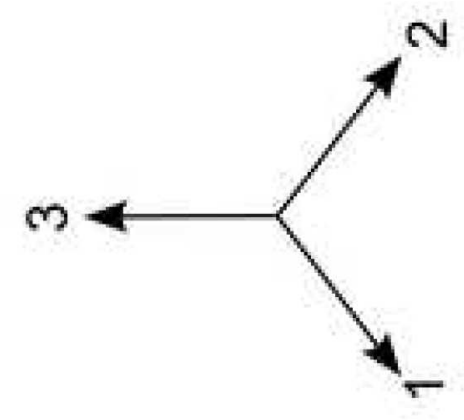

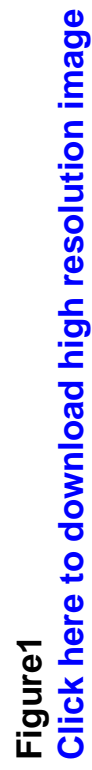
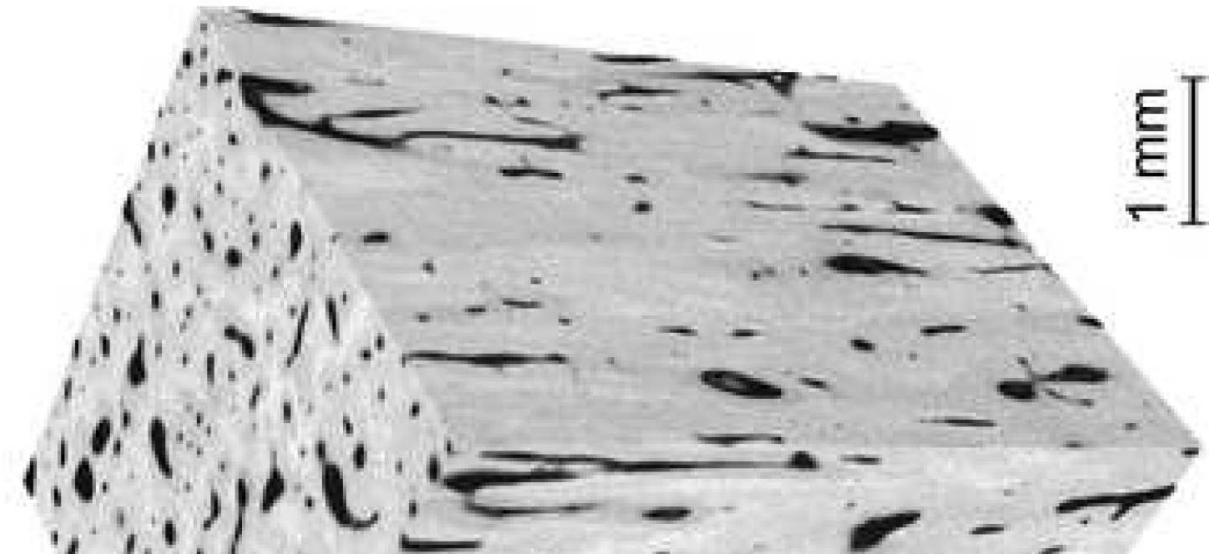

8

a.

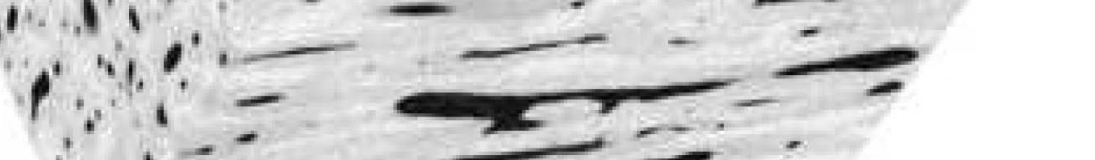




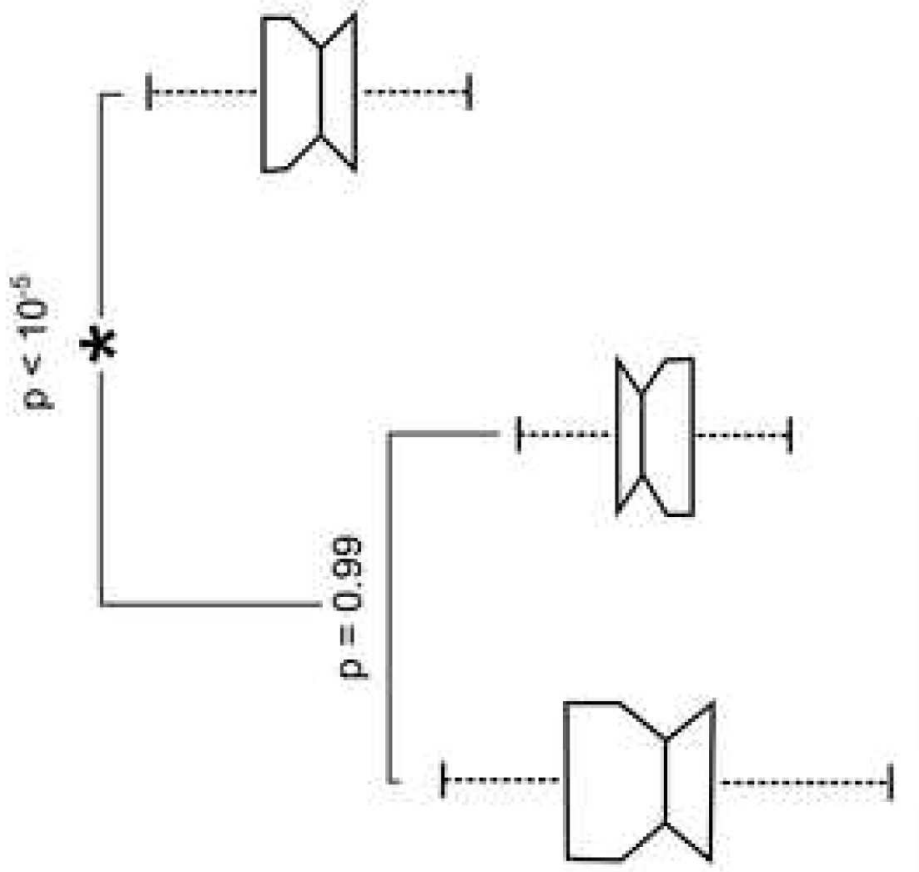

$N$

N

N

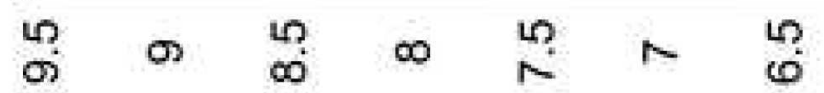

[KReyW] aouepadu! onsnooe ueaw xı!eW

$\Omega$

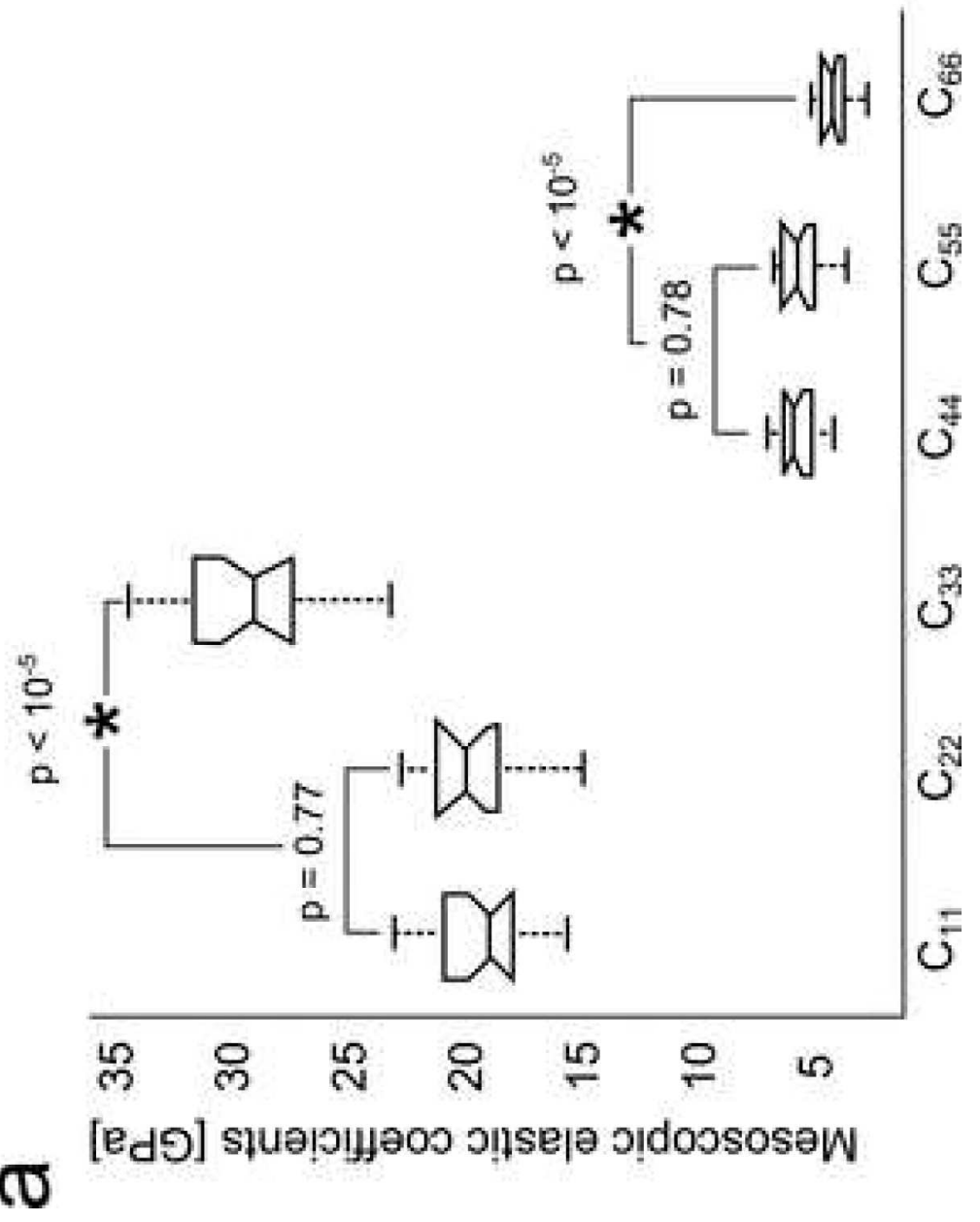




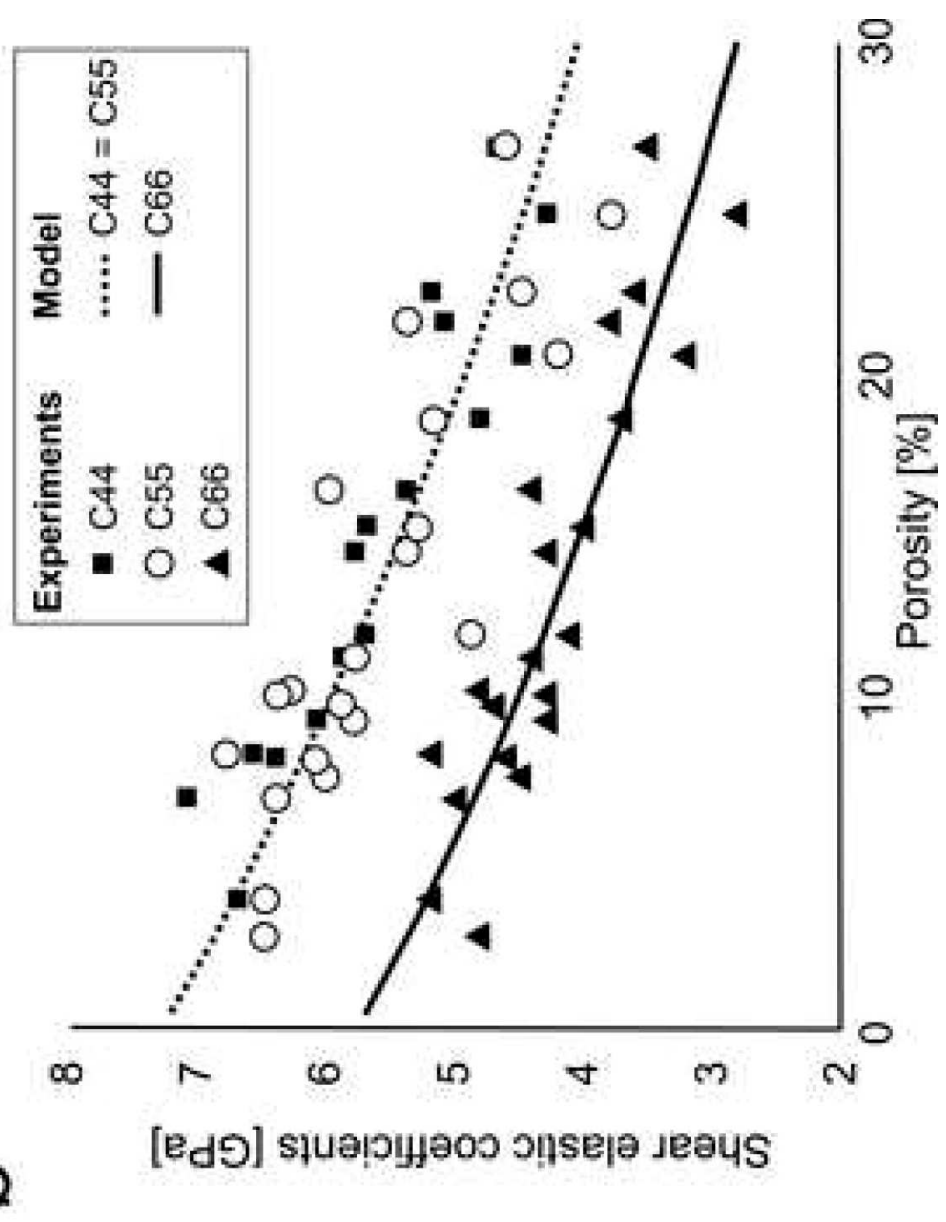

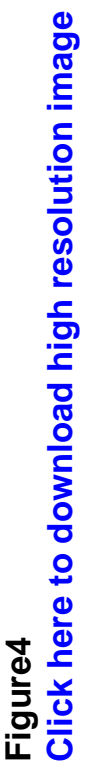

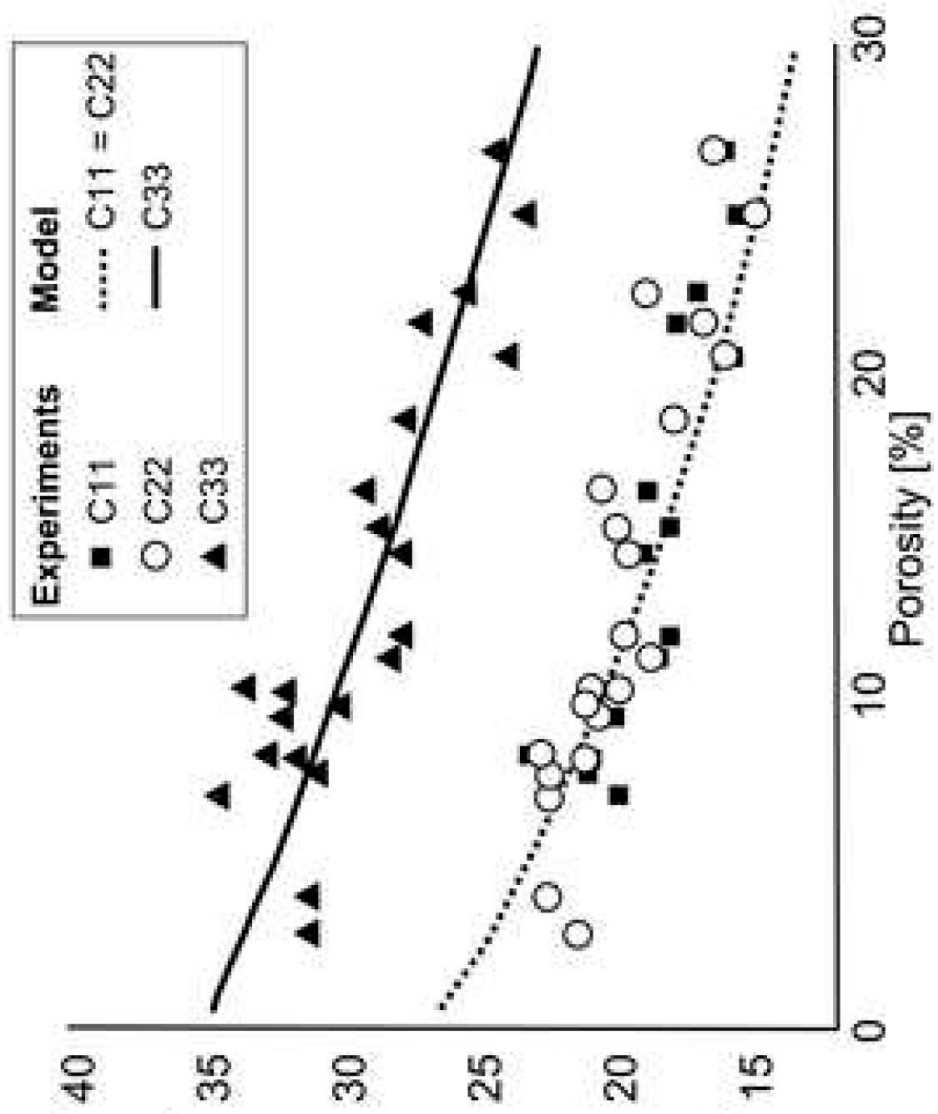

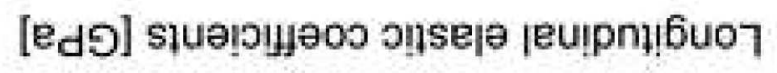




\begin{tabular}{cccccc}
\hline \multicolumn{7}{l}{ Mesoscopic elastic coefficients [GPa] } \\
\hline$C_{11}$ & $C_{22}$ & $C_{33}$ & $C_{44}$ & $C_{55}$ & $C_{66}$ \\
$19.3 \pm 2.2$ & $19.8 \pm 2.2$ & $29.2 \pm 3.2$ & $5.8 \pm 0.8$ & $5.6 \pm 0.8$ & $4.2 \pm 0.6$ \\
{$[15.6-23.2]$} & {$[15.0-22.8]$} & {$[23.3-34.5]$} & {$[4.3-7.1]$} & {$[3.8-6.8]$} & {$[2.8-5.2]$} \\
\hline Mean acoustic impedance of the bone matrix [MRayl] & $\hat{Z}_{2}$ & $\hat{Z}_{3}$ \\
\hline$\hat{Z}_{1}$ & $7.3 \pm 0.3$ & $8.7 \pm 0.4$ \\
$7.4 \pm 0.4$ & {$[6.7-7.9]$} & {$[8.1-9.6]$} \\
\hline $6.4-8.2]$ & $13.5 \pm 6.8$ \\
\hline Vascular porosity [\%] & {$[2.9-26.9]$} \\
\hline
\end{tabular}




\begin{tabular}{|c|c|c|c|c|c|c|}
\hline $\begin{array}{c}\text { Adjusted R } \\
\text { RMSE [GPa] }\end{array}$ & $C_{11}$ & $C_{22}$ & $C_{33}$ & $C_{44}$ & $C_{55}$ & $C_{66}$ \\
\hline$\hat{Z}_{1}$ & n.s. & n.s. & n.s. & n.s. & n.s. & n.s. \\
\hline$\hat{Z}_{2}$ & n.s. & n.s. & n.s. & n.s. & n.s. & n.s. \\
\hline$\hat{Z}_{3}$ & $\begin{array}{c}\mathbf{0 . 2 1} \\
1.96\end{array}$ & n.s. & $\begin{array}{c}0.26^{*} \\
2.75\end{array}$ & $\begin{array}{c}\mathbf{0 . 2 2} \\
0.68\end{array}$ & $\begin{array}{c}\mathbf{0 . 2 6} \\
0.71\end{array}$ & $\begin{array}{c}\mathbf{0 . 1 6} \\
0.59\end{array}$ \\
\hline Por & $\begin{array}{c}\mathbf{0 . 7 9 * *} \\
1.01\end{array}$ & $\begin{array}{l}\mathbf{0 . 7 6} \\
1.09\end{array}$ & $\begin{array}{c}\mathbf{0 . 7 4} \\
1.64\end{array}$ & $\begin{array}{c}\mathbf{0 . 8 4}^{* *} \\
0.31\end{array}$ & $\begin{array}{c}\mathbf{0 . 7 2} \\
0.44\end{array}$ & $\begin{array}{c}\mathbf{0 . 7 8}^{* * *} \\
0.30\end{array}$ \\
\hline Por, $\hat{Z}_{1}, \hat{Z}_{2}, \hat{Z}_{3}$ & $\begin{array}{c}\mathbf{0 . 7 9 * *} \\
1.01\end{array}$ & $\begin{array}{c}0.76^{* * *} \\
1.09\end{array}$ & $\begin{array}{c}0.74^{* *} \\
1.64\end{array}$ & $\begin{array}{c}\mathbf{0 . 8 4} \\
0.31\end{array}$ & $\begin{array}{c}\mathbf{0 . 7 2}^{\text {*** }} \\
0.44\end{array}$ & $\begin{array}{c}\mathbf{0 . 7 8}^{* * *} \\
0.30\end{array}$ \\
\hline
\end{tabular}

n.s.: not significant $(\mathrm{p}>0.05) ;{ }^{*} \mathrm{p}<0.05 ;{ }^{* *} \mathrm{p}<10^{-5}$ 